\title{
Niosome-encapsulated Balanocarpol: compound isolation, characterisation, and cytotoxicity evaluation against human breast and ovarian cancer cell lines
}

\section{Mohammad A. Obeid ${ }^{1 \S *}$, Siti Aisya S. Gany ${ }^{2 \S}$, Alexander I. Gray $^{2}$, Louise Young ${ }^{2}$, John O. Igoli² Valerie A. Ferro ${ }^{2}$}

${ }^{1}$ Department of Pharmaceutical Sciences, Faculty of Pharmacy, Yarmouk University, Irbid, Jordan.

${ }^{2}$ Strathclyde Institute of Pharmacy and Biomedical Sciences, University of Strathclyde, 161 Cathedral Street, G4 0RE Glasgow, United Kingdom.

$\S$ Authors have equal contributions and are first authors.

*Corresponding author. E-mail Address: m.obeid@yu.edu.jo,Tel: 00962798270457

\section{Abbreviations}

Chol: Cholesterol, SP80: Span 80; PDI: Polydispersity index; ZP: Zeta potential; PBS: phosphate-buffered saline tablets; FBS: Foetal bovine serum; TLC: thin layer chromatography; DLS: dynamic light scattering; TEM: transmission electron microscopy; EE: encapsulation efficiency. 


\section{Graphical abstract}

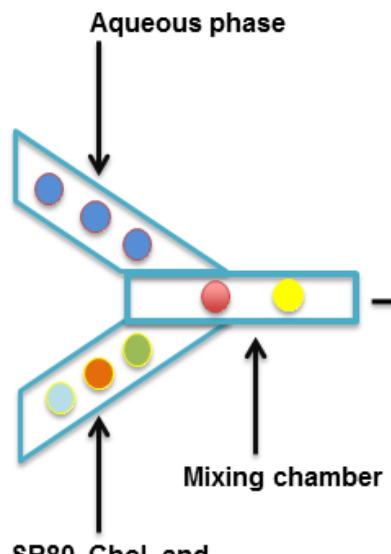

SP80, Chol, and

balanocarpol dissolved in ethanol

Microfluidic mixing

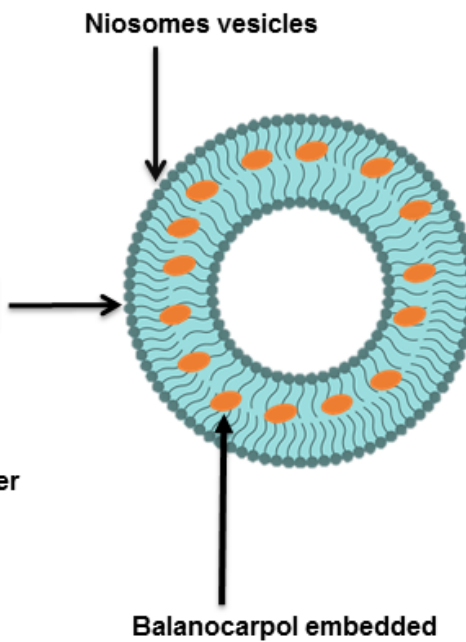

in the membrane bilayer
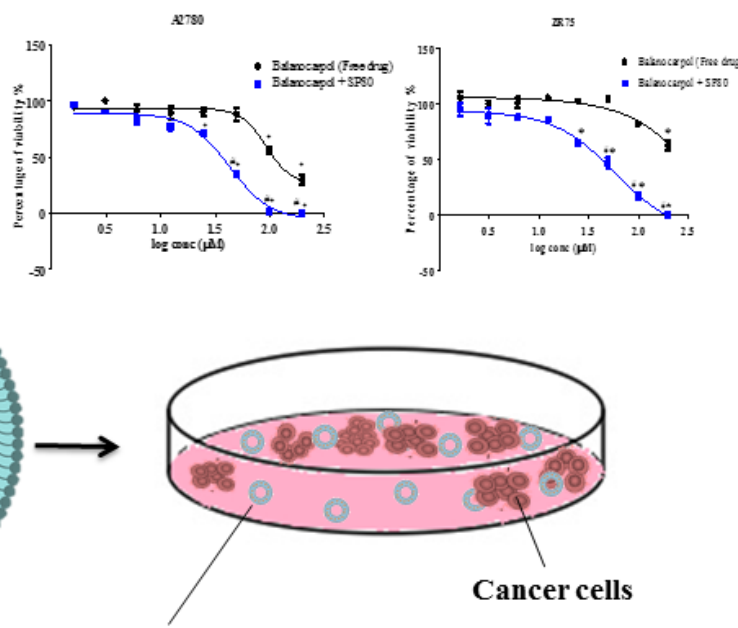

Balanocarpol-loaded niosome

Delivery system

Cancer cells killing 


\section{Abstract}

Natural products have been successfully used for treating various ailments since ancient times and currently there are several natural product based anti-cancer agents used as the main therapy to treat cancer patients or as a complimentary treatment to chemotherapy or radiation. Balanocarpol, which is a promising natural product that has been isolated from Hopea dryobalanoides, has been studied as a potential anticancer agent but its application is limited due to its high toxicity, low water solubility, and poor bioavailablity. Therefore, the aim of this study was to improve the balanocarpol characteristics and improve its anticancer activity through its encapsulation into a bilayer structure of a lipid-based nanoparticle drug delivery system where the application of nanotechnology can help in improving such limitations of balanocarpol. The compound first was extracted and isolated from $H$. dryobalanoides. Niosome nanoparticles composed of span 80 (SP80) and cholesterol were formulated through innovative microfluidic mixing method for the encapsulation and delivery of balanocarpol. The prepared particles were spherical, small, and uniform with an average particles size and polydispersity index $\sim 175 \mathrm{~nm}$ and 0.088 respectively. The encapsulation of balanocarpol into the SP80 niosomes resulted in an encapsulation efficiency of $\sim 40 \%$. The niosomes formulation loaded with balanocarpol showed superior anticancer effect over the free compound when tested in vitro on human ovarian carcinoma (A2780) and human breast carcinoma (ZR-75-1). This is the first study that report the use of SP80 niosomes for successful encapsulation and delivery of balanocarpol into cancer cells.

\section{Key Words}

Niosomes, Microfluidic mixing, Balanocarpol, Drug delivery 


\section{Introduction}

Cancer is a major Public Health problem and the second leading cause of death in the world. The World Health Organization reported a total of 9.5 million deaths worldwide with 616,714 deaths in the US and 1.9 million in Europe. Breast cancer accounts for the highest cancer (2.1 million) cases occurring in women and it is estimated that 627,000 women died from breast cancer in 2018 (1). In the US, 22,240 women were diagnosed with ovarian cancer in 2018, although it only accounts for a small percentage of incidence in woman compared to other types of cancer. Nevertheless, it has a high death rate as it is hard to detect at an early stage and therefore patients are usually diagnosed at its advanced stages $(2,3)$.

Natural products have been successfully used for treating various ailments since ancient times and to date almost $73 \%$ of current pharmaceuticals are derived from natural products (4). Secondary metabolites or organic small molecules such as alkaloids, terpenoids, flavonoids, phenolics, glycosides, polyketides and peptides produced by plants have high potential for drug development, including anti-cancer therapeutics. There are several natural product based anticancer agents used as the main therapy to treat cancer patients or as a complimentary treatment to chemotherapy or radiation $(5,6)$. For example, homoharringtonine, an alkaloid from the bark of Cephalotaxus harringtonii (Japanese plum yew) has been approved by the FDA to treat patients with chronic myeloid leukaemia in different countries such as China, Japan, Pakistan, USA and Germany (7). Another FDA approved drug paclitaxel (also known as Taxol ${ }^{\circledR}$ ) from the bark of Taxus brevifolia (Pacific yew) tree is the most well-known natural product derived drug to treat cancer in the United States. It is used in the treatment of breast, lung, and ovarian cancer, as well as Kaposi's sarcoma $(8,9)$.

Balanocarpol has been isolated from Hopea dryobalanoides (10). The plant is one of the Hopea species from the family Dipterocarpaceae found in the Malaysian rain forest. This family is 
also known to produce a variety of resveratrol oligomers and balanocarpol is one of the major oligoresveratrol compounds found in many Hopea species (11-13). Lim et al. (2012) have shown that resveratrol and its dimers, ampelopsin A and balanocarpol, are inhibitors of sphingosine kinase 1 (SK-1) activity which catalyses formation of the bioactive lipid, sphingosine 1-phosphate that serves to protect cancer cells from apoptosis. They also showed that balanocarpol stimulated Poly (ADP-ribose) Polymerase (PAPRP) cleavage, reduced DNA synthesis and down-regulation of SK-1 expression. One molecule of balanocarpol appears to bind to at least two SK-1 catalytic molecules to reduce the activity of each simultaneously, thus perturbing SK-1-mediated signalling in MCF-7 breast cancer cells. However, despite its potential therapeutic effects, it has high toxicity and low water solubility thus limiting its clinical application $(14,15)$. Resveratrol and its dimers have low water solubility and bioavailability due to deprotonation of their hydroxyl groups $(16,17)$. The aim of this study is to improve the drug characteristics of balanocarpol and increase its cytotoxicity against the cancer cells through its encapsulation into a bilayer structure of a lipid-based nanoparticle drug delivery system.

Nanoparticle drug delivery systems is one approach to improve the physicochemical characteristics and the pharmacokinetic properties of many therapeutic agents. Most of these have been associated with limitations such as high toxicity, poor absorption rate, high rate of elimination which limits their bioavailability and subsequent pharmacological benefits (18). In particular, the bioavailability and pharmacokinetics of water insoluble drugs face some challenges against accumulation of drug in target cells. However, these limitations can be overcome by the use of drug delivery systems which can enhance the bioavailability of such therapeutic agents (19).

Niosomes were introduced in the 1970s in cosmetic preparations and were subsequently proposed for the delivery of therapeutic agents. Typically, niosomes can be formulated from a 
variety of non-ionic surfactants, cholesterol and lipid mixtures with different compositions (20). Similar to liposomes, niosomes are spherical vesicles composed of a bilayer structure encapsulating an aqueous core. Hydrophilic drugs can be incorporated in the aqueous core while hydrophobic drugs can become embedded into the lipid bilayer structure (21). Different methods can be used for the preparation of niosomes such as the thin film hydration method, ether injection method, and microfluidic mixing. The latter allows for the production of size controlled particles in a very short period of time with a low size distribution (22).

Other types of drug delivery systems have been applied for the delivery of different therapeutic agents in an attempt to improve the solubility and reduce the toxicity such as dendrimers, metal nanoparticles, silica nanoparticles, carbon nanotubes, and many others. However, lipid based nanoparticles such as liposomes and niosomes are among the mostly studied types of nanoparticles in drug delivery $(3,23)$.

Niosomes composed of span 80 (SP80) and cholesterol at a 1:1 molar ratio and synthesised by microfluidic mixing have been used for the encapsulation of nucleic acids and curcumin (2426). The niosomes where characterised for their physicochemical properties, encapsulation efficiency, cytotoxicity, and in vitro effects in comparison with the free un-encapsulated drug. The encapsulation of balanocarpol in niosomes similarly produced to provide a means of reducing toxicity, enhancing its bioavailability and the anti-cancer effects of the compound against ovarian and breast cancer cells is reported.

\section{Materials and methods}

\subsection{Materials}

Sorbitan monooleate (span 80, SP80), cholesterol (Chol), phosphate-buffered saline tablets (PBS, pH 7.4), alamarBlue ${ }^{\circledR}$, serum-free and antibiotic-free Roswell Park Memorial Institute medium (RPMI 1640), L-glutamine, and penicillin-streptomycin were purchased from Sigma- 
Aldrich (UK) (all at cell culture grade). Foetal bovine serum (FBS) was purchased from Biosera (UK). Human ovarian carcinoma (A2780) and human breast carcinoma (ZR-75-1) were purchased from the European Collection of Authenticated Cell Cultures (ECACC). A sample of dried and ground bark of $H$. dryobalanoides originally collected by the Forest Research Institute of Malaysia (FRIM) and stored at the Strathclyde Innovations in Drug Research (SIDR) were used for the study.

\subsection{Extraction and isolation of balanocarpol from $\boldsymbol{H}$. dryobalanoides}

The air-dried and powdered bark of $H$. dryobalanoides $(500 \mathrm{~g})$ was extracted with $n$-hexane, ethyl acetate and then methanol in a Soxhlet extractor for 4-5 days for each solvent. The extracts were filtered and evaporated using a rotary evaporator to obtain the solvent free extracts. The ethyl acetate extract $(8.1 \mathrm{~g})$ was subjected to column chromatography on silica gel (mesh size $0.063-0.200 \mathrm{~mm}$ ), eluted with $n$-hexane-ethyl acetate mixtures of increasing polarity $(9: 1,7: 3,5: 5,4: 6,3: 7)$ to obtain fractions that were then pooled if they showed similar thin layer chromatography (TLC) profiles. Balanocarpol was detected in Fraction 4 (12) based on its NMR proton signals. Sephadex ${ }^{\circledR}$ LH20 (Sigma-Aldrich, bead size 25-100 $\mu \mathrm{m}$ ) was used to purify the balanocarpol, eluting isocratic with methanol to obtain $273.0 \mathrm{mg}$ of the compound.

\subsection{Preparation of SP80 Niosomes}

Niosomes, composed of SP80 and chol at a 50:50 molar ratio, were prepared by microfluidic mixing using a NanoAssemblrTM (Benchtop, Precision NanoSystems Inc., Vancouver, Canada) as described previously (22). The organic phase was prepared by dissolving the lipid components with and without balanocarpol in ethanol. The final balanocarpol concentration in the lipid phase before mixing with the aqueous phase (deionised water) was $1 \mathrm{mM}$. The mixing parameters were adjusted to a 1:1 ratio between the aqueous and the lipid phase and the two phases were mixed at $1 \mathrm{ml} / \mathrm{min}$ at $50{ }^{\circ} \mathrm{C}$ using a heating block. 


\subsection{Removal of un-encapsulated drug}

The niosomes encapsulating balanocarpol were transferred to a dialysis tubing (cellulose membrane avg. flat width $10 \mathrm{~mm}$, molecular weight cut-off $14000 \mathrm{Da}$, Sigma Aldrich, UK) and dialysed against 10x volume of deionised water to remove un-encapsulated drug. Samples were taken every hour from the dialysis tubing and the amount of balanocarpol was determined based on its UV absorbance at $285 \mathrm{~nm}$ using a HELIOS ALPHA ThermoSpectronic spectrophotometer (Thermo Fisher Scientific, UK). Dialysis was carried out until no more balanocarpol was detected.

\subsection{Physicochemical characterisation of niosomes}

\subsubsection{Particles size analysis}

The size distribution (mean diameter and polydispersity index (PDI) of the niosomes with and without drug was measured by dynamic light scattering (DLS) using a Zetasizer Nano-ZS (Malvern Instruments Ltd., UK). Samples were prepared at 1/20 dilution in deionised water and triplicate measurements were taken at $25^{\circ} \mathrm{C}$.

\subsubsection{Niosome morphology}

Morphological examination of the niosomes was carried out using transmission electron microscopy (TEM). Briefly, Carbon-coated copper grids (400 mesh, agar scientific) were glow discharged in air for 30 seconds. Sample solution ( $3 \mathrm{ul}$ ) was drop-cast on the grids and then negatively stained using uranyl acetate. Each sample was allowed to dry afterwards in a dustfree environment prior to TEM imaging. The dried samples were imaged using a JEOL JEM1200EX TEM (JEOL, Tokyo, Japan) operating at an accelerating voltage of $80 \mathrm{kV}$. 


\subsubsection{Determination of drug encapsulation efficiency}

After removal of the free drug by dialysis, $100 \mu \mathrm{l}$ of the niosome formulation was mixed with $100 \%$ methanol to lyse the niosomes particles and release the entrapped drug. The released balanocarpol was determined using a calibration curve of the pure drug in methanol at the wavelength of $285 \mathrm{~nm}$. The encapsulation efficiency (EE) of balanocarpol was determined as a percentage of the initial balanocarpol concentration $(500 \mu \mathrm{M}$ after mixing with the aqueous phase). The experiments were performed in triplicate and the average \pm SD was reported.

\subsection{Cell culture}

Human ovarian carcinoma (A2780) and human breast carcinoma (ZR-75-1) were cultured in sterile Costar T75 flasks containing RPMI (Gibco, Hong Kong, China), supplemented with FBS $(10 \%, \mathrm{v} / \mathrm{v}), 2 \mathrm{mM}$ glutamine, $1 \%(\mathrm{v} / \mathrm{v})$ penicillin and streptomycin at $37{ }^{\circ} \mathrm{C}$ in an atmosphere of $5 \% \mathrm{CO}_{2}(100 \%$ humidity). At approximately $70 \%-80 \%$ confluency, cells were detached from the culture flask by treatment with TrypLE express (Gibco), and a suspension of $4 \times 10^{3}$ cells $/ \mathrm{mL}$ of viable cells was seeded in a flat bottomed 96-well plate (Costar, Washington, DC, USA) and incubated at $37^{\circ} \mathrm{C}, 5 \% \mathrm{CO}_{2}$ and $100 \%$ humidity.

\subsection{Cytotoxicity assay of babanocarpol}

The balanocarpol (free and encapsulated) were evaluated in an in vitro cytotoxicity assay using an AlamarBlue ${ }^{\circledR}$ based test. Cells $\left(4 \times 10^{3}\right.$ cells $\left./ \mathrm{mL}\right)$ were seeded into flat bottomed 96 -well plates and incubated overnight at $37^{\circ} \mathrm{C}, 5 \% \mathrm{CO}_{2}$ and $100 \%$ humidity. Cells were treated with various concentrations of compound dissolved in dimethyl sulfoxide (DMSO) for $24 \mathrm{~h}$. The negative control consisted of cells treated with $1 \%$ DMSO only. Next, cells were incubated with $10 \mu$ of AlamarBlue ${ }^{\circledR}\left(10 \%\right.$ of sample volume) at $37^{\circ} \mathrm{C}$ for $4-5$ hours then read in a SpectraMax M5 plate reader, at a fluorescence excitation wavelength of 560nm (peak excitation is $590 \mathrm{~nm})$. The results were expressed as a mean \pm Standard Error of the Mean 
(SEM) of triplicate readings. Viable cells following treatment were calculated as a percentage of the untreated control cells.

\subsection{In vitro cytotoxicity of niosomes on cancer cell lines}

Empty niosomes were assessed for cytotoxicity on ZR75 and A2780 cells in order to determine the non-toxic concentration of the niosomes. Each cell line was seeded in a 96-well plate at a density of $1 \times 10^{4}$ per well in growth medium and incubated at $37{ }^{\circ} \mathrm{C}, 5 \% \mathrm{CO}_{2}$ and $100 \%$ humidity for $24 \mathrm{~h}$. The cells were treated with a range of concentrations of niosomes starting at $1250 \mu \mathrm{g} / \mathrm{ml}$ and serially diluted throw-out the plate. DMSO was used as a positive kill control and one column per plate contained untreated cells and medium. The cells were incubated for $24 \mathrm{~h}$ and then treated with $20 \mu \mathrm{L}$ resazurin $(0.1 \mathrm{mg} / \mathrm{ml})$ to each well and incubated for a further

$24 \mathrm{~h}$. The transformation of resazurin into resorufin by the live cells was then detected by measuring the absorbance at 560 - $590 \mathrm{~nm}$ using a SpectraMax M5 plate reader (Molecular Devices, Sunnyvale, CA, USA). The cell viability was calculated as a percentage of the absorbance from the treated cells with niosomes to the absorbance of the untreated cells.

\subsection{Statistical analysis}

Statistical analysis was carried out using GraphPad Prism 5.0, via two-way Analysis of Variance (ANOVA); with the assumption the data was parametric and independent of each other. Each sample was repeated in triplicate; mean and SEM or SD were analysed. $\mathrm{P}<0.001$ was considered significant. To identify the points of variance, Bonferroni correction was applied as a post-hoc test. 


\section{Results and discussion}

\subsection{Physicochemical characterisation of niosomes}

\subsubsection{Particles size analysis}

The average particle size and PDI for SP80 niosomes with and without balanocarpol are given in Table 1. The empty and loaded SP80 niosomes were small in size $(<200 \mathrm{~nm})$ with a uniform particle size distribution. However, the average particle size of the empty niosomes was slightly but not significantly $(\mathrm{p}>0.05)$ larger than that of the balanocarpol niosomes. This suggests that the compound had an effect on the packing and distribution of the lipid components through the niosome membrane bilayer since balanocarpol is hydrophobic and will be encapsulated in the bilayer structure of the niosomes vesicles. The encapsulation of the balanocarpol into the membrane bilayer might make the bilayer structure more packed which will make the loaded niosomes slightly smaller than the empty vesicles. However, as indicated above, this difference was not significant.

Table 1. Particle size analysis for SP80 niosomes

\begin{tabular}{|c|c|c|}
\hline Sample & Z $_{\text {Average }} \pm$ SD & PDI \pm SD \\
\hline Empty SP80 niosomes & $175.60 \pm 0.95$ & $0.088 \pm 0.017$ \\
\hline SP80 niosomes encapsulating balanocarpol & $160.60 \pm 1.48$ & $0.096 \pm 0.005$ \\
\hline
\end{tabular}

\subsubsection{Niosome morphology}

Figure 1 shows the morphology of the SP80 niosomes using TEM at $200 \mathrm{~nm}$ scale that indicates they are spherical in shape with a particle size comparable with the DLS results. These results matched those previously reported for other types of niosomes prepared by microfluidics (21, 22). 


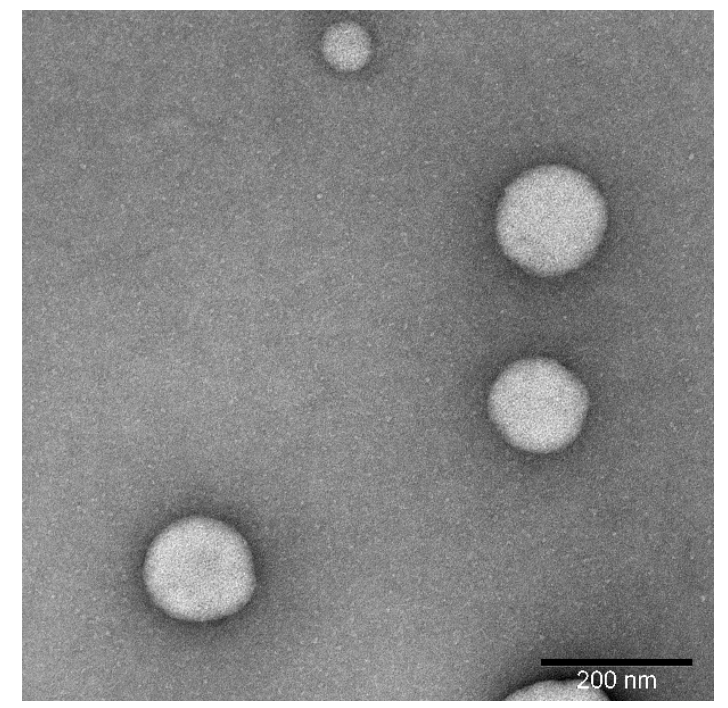

Figure 1. TEM analysis of empty SP80 niosomes.

\subsubsection{Niosome encapsulation efficiency}

The encapsulation of balanocarpol resulted in an EE value of $39.32 \% \pm 0.28$. Niosomes are versatile nanoparticles as they allow encapsulation of hydrophilic compounds in their aqueous core and hydrophobic compounds such as balanocarpol into the bilayer (22). While the encapsulation of hydrophilic compounds significantly affects niosome size where higher encapsulation can be achieved using large unilamellar vesicles, this is not the case for hydrophobic molecules. The encapsulation of hydrophobic molecules might be affected by the lamellarity level where higher encapsulation can be achieved using multilamilar vesicles (20). Furthermore, the types of the lipid components used in niosome manufacturing and the quantity of cholesterol in the formulation will also have a major effect on the encapsulation of hydrophobic drugs. Cholesterol increases the rigidity and decreases the fluidity of the membrane bilayer and higher encapsulation of hydrophobic drugs can be achieved for less rigid membranes (20). 
Since this is the first time encapsulation of balanocarpol into SP80 niosomes has been described, the results obtained from this study indicate that the preparation of niosomes with microfluidic mixing allowed for good encapsulation with high EE results of this hydrophobic drug. These results were comparable with what has been reported in the literature for the encapsulation of hydrophobic drugs into lipid nanoparticles. For example, Kastner et al. were able to achieve a maximum encapsulation efficiency for propofol, which is a poorly water soluble drug, of about $50 \mathrm{~mol} \%$ using different liposome formulations prepared by microfluidic mixing (27).

The production of niosomes using microfluidic mixing is a fast and reliable technique which can prepare small and monodisperse niosomes within seconds (24). This is an important point to consider when developing formulations on industrial scale which is not easy using traditional methods such as the thin film hydration method. Recently, several studies have applied the microfluidic mixing for nanoparticles preparation in an attempt to provide a reliable method for large scale production of nanoparticles which will have significant impact on the future of the nanomedicine industry $(25,28)$.

\subsubsection{Empty niosome toxicity}

Figure 2 shows the cytotoxicity of the empty niosomes on A2780 and ZR-75-1 cell lines. The aim of this study was to determine the non-toxic concentration of the niosomes to be used to deliver balanocarpol. Concentrations lower than $625 \mu \mathrm{g} / \mathrm{ml}$ were not toxic for both cell types with $100 \%$ viability. However, at a niosome concentration of $1250 \mu \mathrm{g} / \mathrm{ml}$, the A2780 cells were $50 \%$ viable while the ZR-75-1 cells remained $100 \%$ viable. At the highest concentration of the SP80 niosomes $(2500 \mu \mathrm{g} / \mathrm{ml})$, the ZR-75-1 cells were around $80 \%$ viable while the viability of the A2780 cells were only $25 \%$. These results were taken into consideration when applying the balanocarpol-loaded niosomes to the cells in subsequent experiments and the niosome 
concentration used was $625 \mu \mathrm{g} / \mathrm{ml}$ to ensure any effect on the cells was a result of the drug rather than of the nanoparticle.

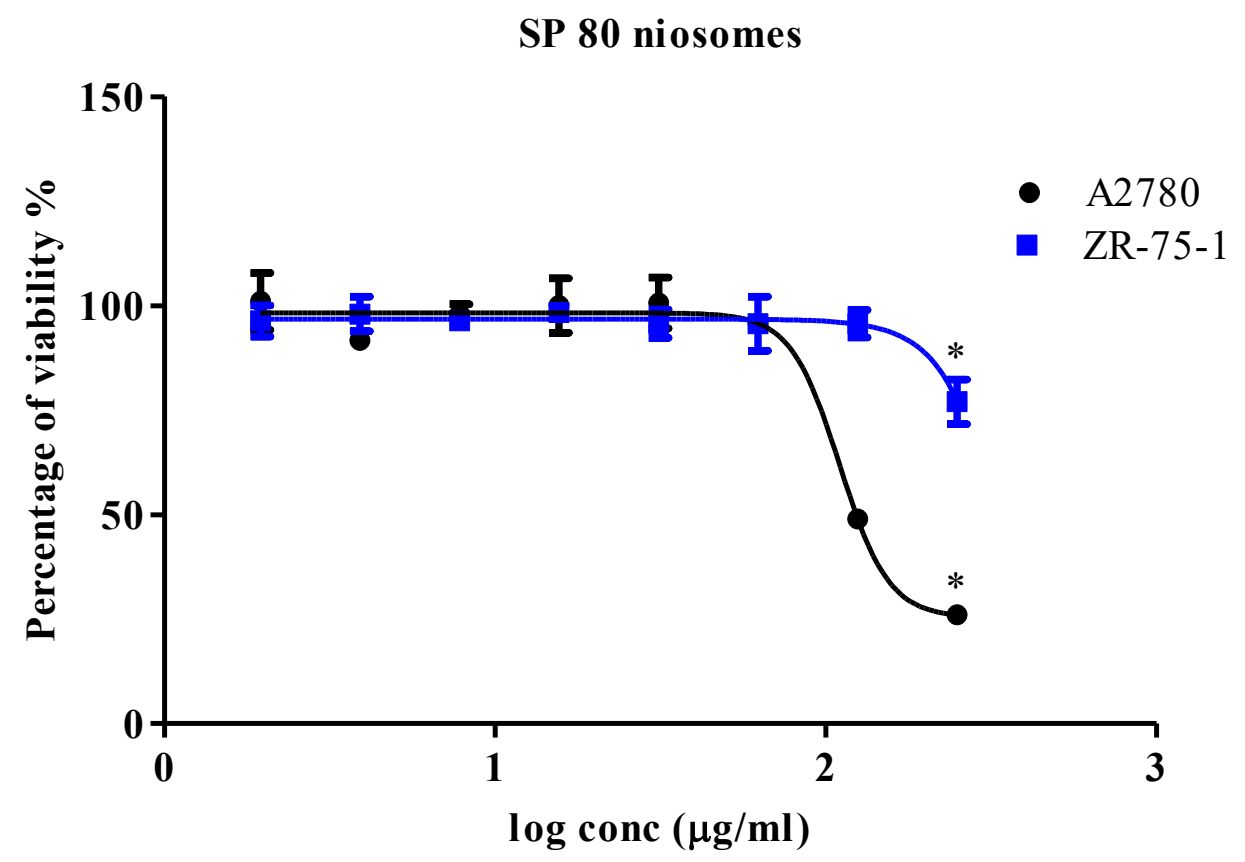

Figure 2. Percentage cell viability of A2780 (a) and ZR-75-1 (b) cells at indicated concentrations of SP80 niosomes (ranging from 19.5-2500 $\mu \mathrm{g} / \mathrm{ml}$ ) for $24 \mathrm{~h}$. The cell viability was measured using alamarBlue ${ }^{\circledR}$. Results are expressed as a percent of cell viability normalised to control cells (untreated). Results represent the mean with SEM from three independent experiments. Statistical significance of sample in comparison to control is denoted by $* \mathrm{p}<0.001$. 


\subsection{Characterisation and cytotoxicity of balanocarpol}

Balanocarpol was isolated as a yellow solid and the molecular formula $\mathrm{C}_{28} \mathrm{H}_{22} \mathrm{O}_{7}$ was assigned from LCMS-HRESI (positive mode) spectrum which gave an $[\mathrm{M}+\mathrm{H}]^{+}$ion at $\mathrm{m} / \mathrm{z} 471.1441$ (calc. $471.1444 \mathrm{C}_{28} \mathrm{H}_{23} \mathrm{O}_{7}$ ). This was supported by the ${ }^{1} \mathrm{H}$ and ${ }^{13} \mathrm{C}$ NMR data given in Table 2 and figure 3 which is consistent with the report by Atun S. et al. (13). Balanocarpol (Figure 4) was first isolated in 1985 by Diyasena et al. from the bark acetone extracts of Balanocurpus zeylanicus and $H$. jucunda (11). The compound has also been isolated from $H$. dryobalanoides bark (29) and other Hopea sp. such as H. parviflora (30) and H. mengarawan (13).

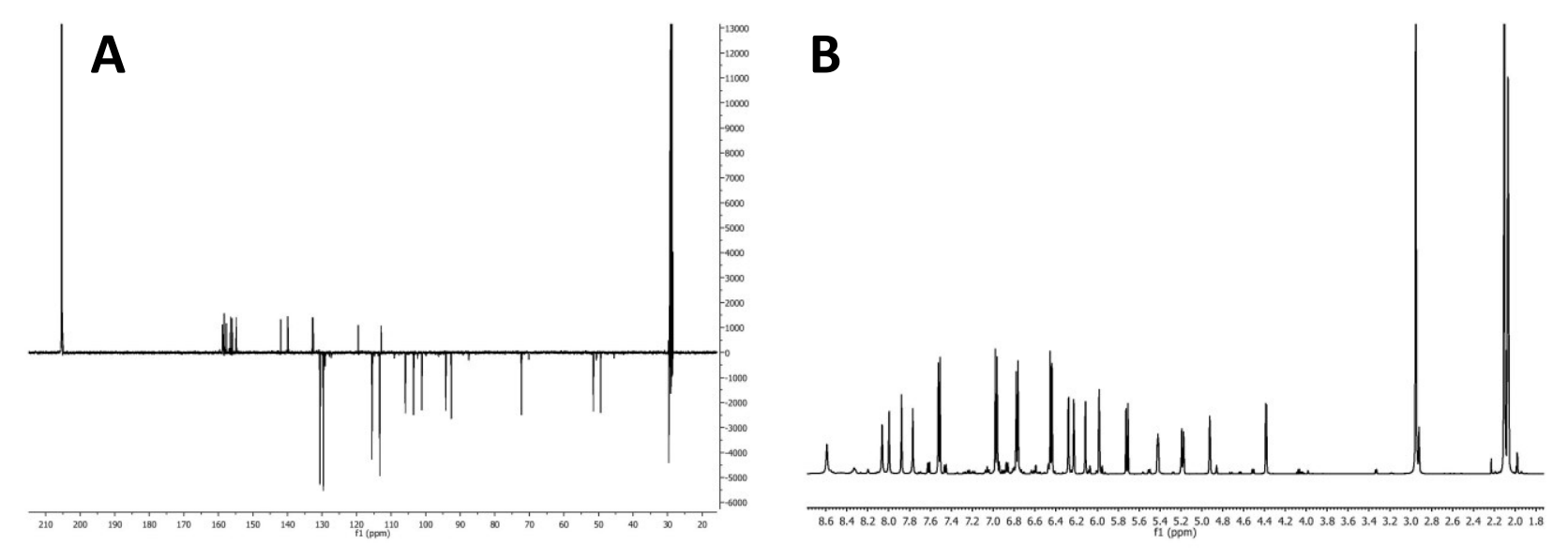

Figure 3. (A) Carbon and (B) proton NMR spectrum of balanocarpol. 
Table 2. NMR data of balanocarpol in acetone-d $\mathrm{d}_{6}$.

\begin{tabular}{|c|c|c|}
\hline \multirow[t]{2}{*}{ Position } & \multicolumn{2}{|c|}{ Balanocarpol } \\
\hline & $\delta$ H ppm, mult $(J, \mathrm{~Hz})$ & $\delta \mathrm{C} \mathrm{ppm}$ \\
\hline 1 & - & 132.59 \\
\hline 2,6 & $6.77 d(8.8)$ & 130.71 \\
\hline 3,5 & $6.44 d(8.8)$ & 113.30 \\
\hline 4 & - & 154.89 \\
\hline 7 & $4.92 d(2.0)$ & 49.39 \\
\hline 8 & $5.42 d(6.4)$ & 72.29 \\
\hline 9 & - & 139.92 \\
\hline 10 & - & 112.94 \\
\hline 11 & - & 158.85 \\
\hline 12 & $5.98 d(2.1)$ & 94.45 \\
\hline 13 & - & 158.31 \\
\hline 14 & $6.11 d(2.14)$ & 103.57 \\
\hline 1 ' & - & 132.83 \\
\hline $2^{\prime}, 6^{\prime}$ & $7.52 d(8.5)$ & 129.62 \\
\hline $3^{\prime}, 5^{\prime}$ & $6.97 d(8.5)$ & 115.57 \\
\hline 4 ' & - & 157.67 \\
\hline 7 & $5.72 d(9.5)$ & 92.63 \\
\hline $8^{\prime} \mathrm{OH}$ & $5.18 d(9.5)$ & 51.46 \\
\hline 9' & - & 141.98 \\
\hline $10^{\prime}$ & - & 119.57 \\
\hline $11^{\prime}$ & - & 156.53 \\
\hline $12^{\prime}$ & $6.28 d(2.4)$ & 101.14 \\
\hline $13^{\prime}$ & - & 156.04 \\
\hline $14^{\prime}$ & $6.23 d(2.4)$ & 105.95 \\
\hline $\mathrm{OH}$ & $\begin{array}{l}4.39 d(4.37,8 \mathrm{a}-\mathrm{OH}), 7.77 \\
7.88,8.00,8.06,8.59 \text { each } s\end{array}$ & \\
\hline
\end{tabular}




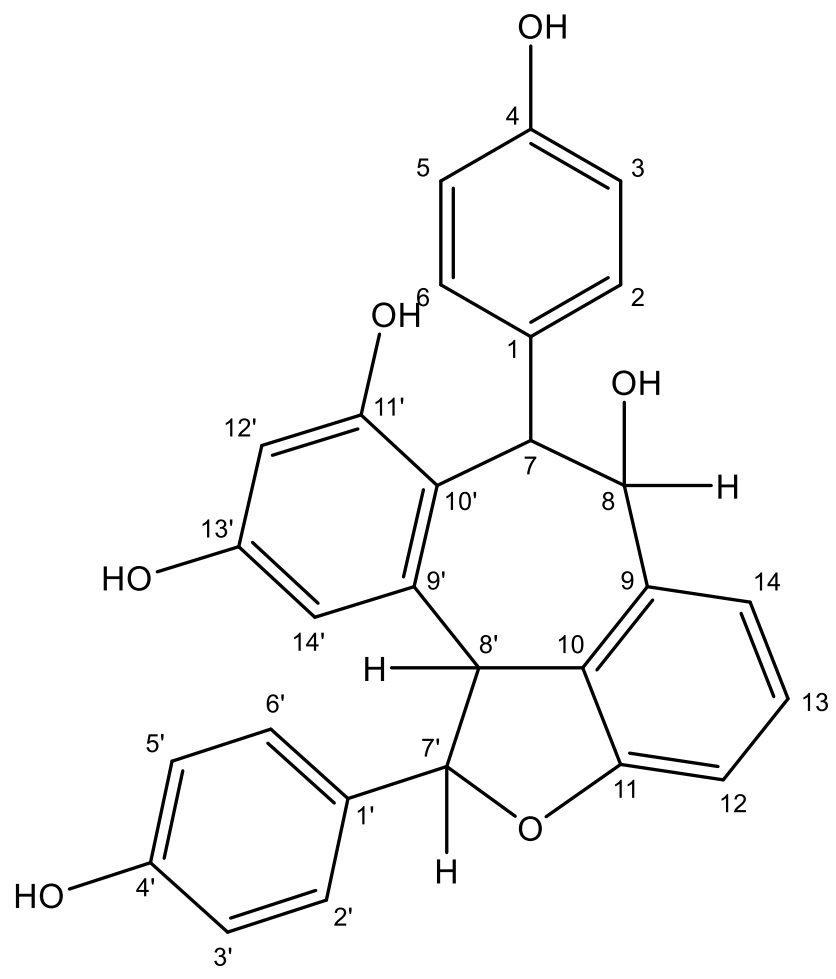

Figure 4. Balanocarpol 
A2780

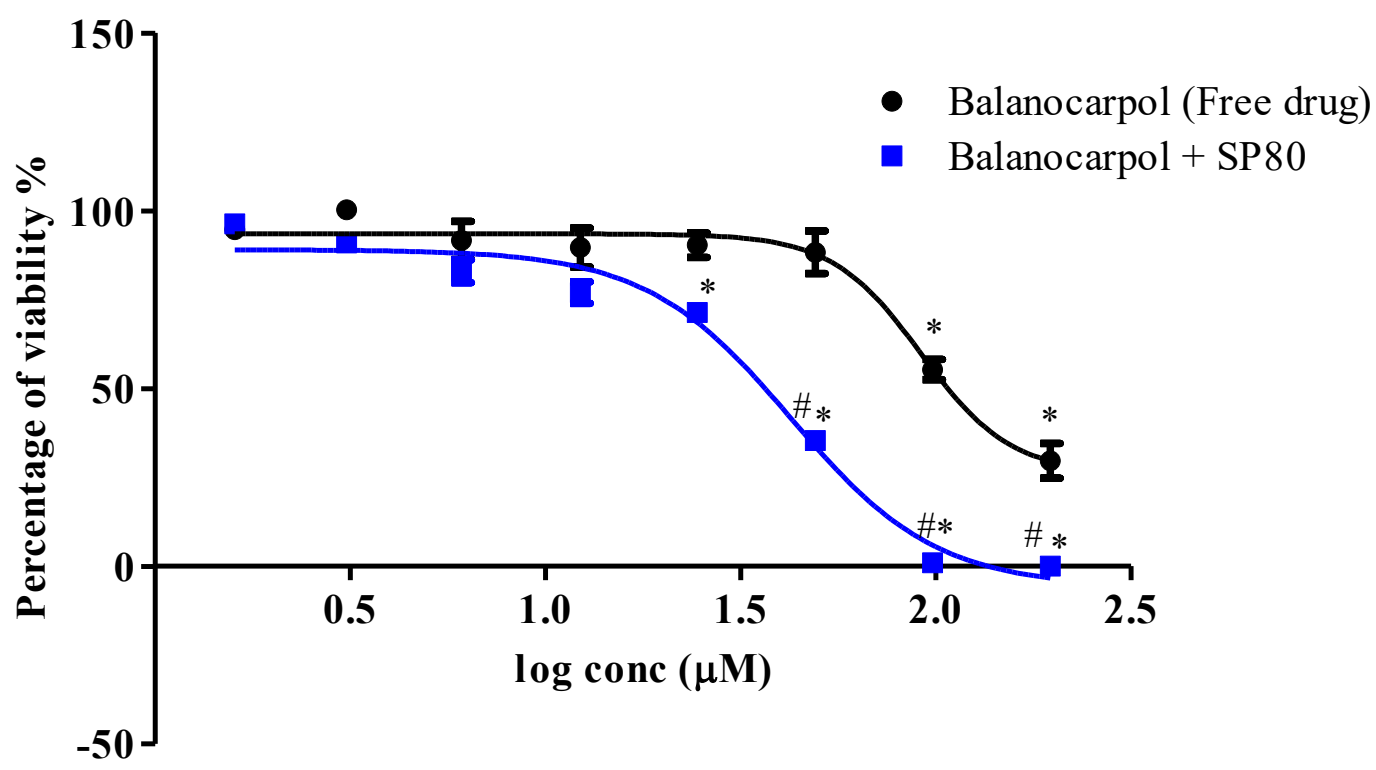

ZR75

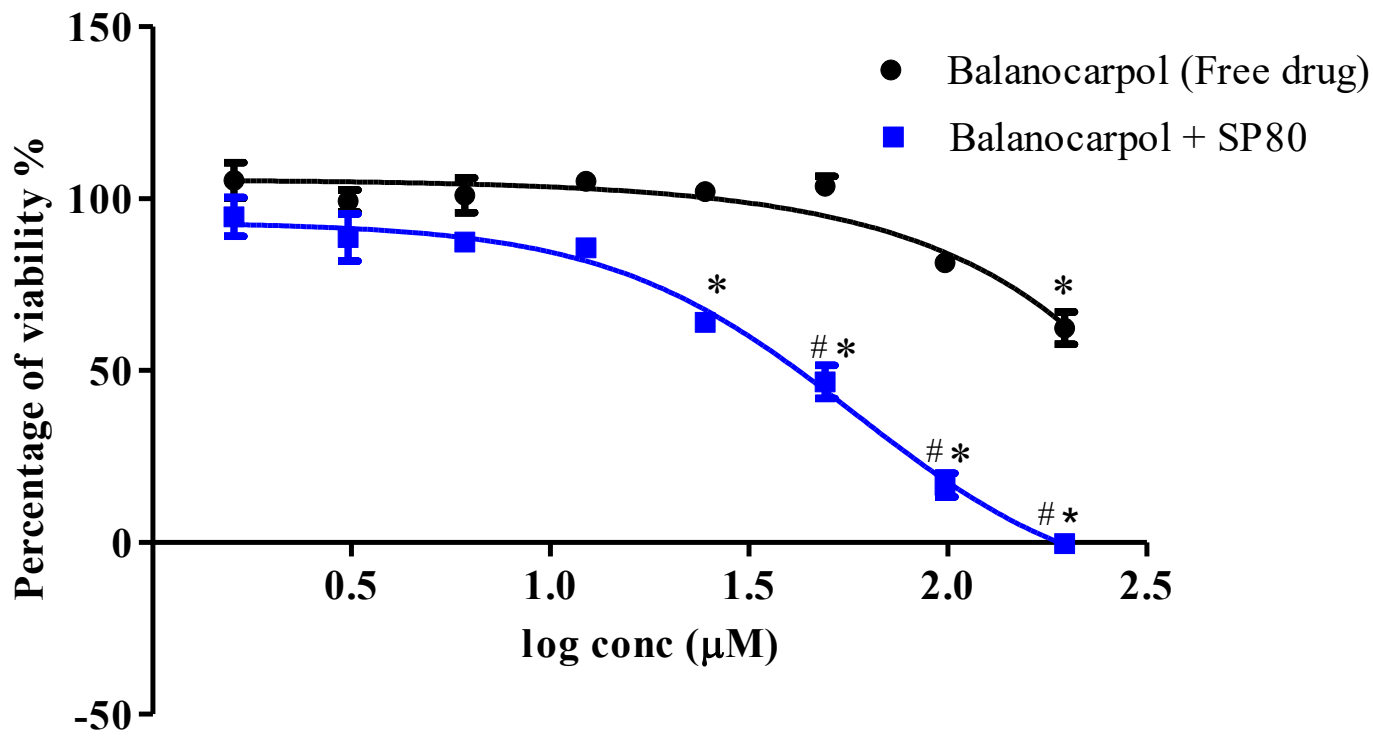

Figure 5. Percentage cell viability of balanocarpol and balanocarpol+SP80 (SP80 encapsulated balanocarpol) in A2780 (a) and ZR-75-1 (b) cells at indicated concentrations (1.6, 3.1, 6.1, 12.3, 24.5, 49.1, 98.3 and 196.6) for $24 \mathrm{~h}$. The cell viability was measured using alamarBlue ${ }^{\circledR}$. Results are expressed as percent of cell viability normalised to control cells (untreated). The results represent mean with SEM from three independent experiments. Statistical significance 
of sample in comparison to control is denoted by ${ }^{*} \mathrm{p}<0.001$ and balanocarpol $+\mathrm{SP} 80$ in comparison with balanocarpol (Free drug) is denoted by $\# \mathrm{p}<0.001$.

The cytotoxicity of balanocarpol+SP80 against the A2780 and ZR-75-1 cell lines after $24 \mathrm{~h}$ was assessed with alamarBlue ${ }^{\circledR}$ and showed in figure 5 . The highest concentration of balanocarpol $(196.6 \mu \mathrm{M})$ is based on the $39.32 \%$ entrapment efficiency of the initial balanocarpol concentration $(500 \mu \mathrm{M})$. Bala-SP80 exhibited significantly $(\mathrm{p}<0.001)$ higher cytotoxicity at $1.6,3.1,6.1,12.3,24.5,49.1,98.3$, and $196.6 \mu \mathrm{M}$ compared to free balanocarpol for both cell lines (Figure 4). In A2780 cell, balanocarpol+SP80 had a lower EC 50 value (42.63 $\mu \mathrm{M})$ compared to free balanocarpol $(91.77 \mu \mathrm{M})$. For ZR-75-1, the highest concentration of free balanocarpol did not reach 50\% toxicity, but balanocarpol+SP80 gave an $\mathrm{EC}_{50}$ value of 57.97 $\mu \mathrm{M}$. Cytotoxicity of Balanocarpol+SP80 against A2780 seems to be slightly better compared to ZR-75-1. At a concentration of $49.1 \mu \mathrm{M}$, balanocarpol+SP80 caused a 2.8 -fold decrease of A2780 cell viability compared to ZR-75-1.

Balanocarpol, belongs to a group of compounds called stilbenes; secondary metabolites produced by plants in response to stressful conditions. Resveratrol oligomers are characterised by the polymerisation of two to eight resveratrol units and are the largest group of oligomeric stilbenes (31). Resveratrol is well known for its anti-cancer activities by upregulating or downregulating different pathways such as reactive oxygen species (ROS), cyclooxygenase (COX), nuclear factor $\kappa \mathrm{B}(\mathrm{NF} \kappa \mathrm{B}), \mathrm{B}$ cell lymphoma-associated X (BAX), B cell lymphoma 2 (Bc12) (32-34). However due to its structure, resveratrol has poor solubility in aqueous solution, low bioavailability and high chemical instability due to its sensitivity to light and a tendency towards autooxidation $(35,36)$. These features are also most likely to effect balanocarpol activity as one phenolic hydroxyl (potential hydration point) has been converted to the 
heterocyclic oxygen of the benzofuran ring system while another phenolic and the carbinol are sterically hindered by the para-hydroxyphenyl ring attached to the cycloheptyl ring (Figure 3).

Balanocarpol has been reported to be able to induce poly ADP ribose polymerase (PARP) cleavage in MCF-7 breast cancer cells, indicating that it inhibits proliferation and induces apoptosis in the cells at a high concentration $(100-300 \mu \mathrm{M})(37)$. It also directly down-regulates sphingosine kinase 1 (SK1) expression and reduces DNA synthesis at the same concentration (12). This is the first report of the cytotoxic effects of balanocarpol on an ovarian cancer cell line, although it has shown cytotoxicity against HeLa (cervical) and Raji (Human Burkitt's lymphoma) cancer cell lines at a high concentration ( $\mathrm{LC}_{50}: 682.16$ and $235.29 \mu \mathrm{g} / \mathrm{ml}$, respectively) (38).

Overall, compared to free balanocarpol, Balanocarpol+SP80 exhibited significantly improved cytotoxicity for both cell lines, which can be attributed to the SP80 niosomes resulting in improved aqueous balanocarpol solubility and enhanced drug uptake by the cells at a higher rate.

\section{Conclusions}

In this study, the encapsulation of the natural product, balanocarpol, into niosomes nanoparticles were reported. The formulation of niosomes nanoparticles for the encapsulation and delivery of balanocarpol showed superior anticancer effect compared to the free balanocarpol. This indicate that the use of niosomes as a delivery system for the encapsulation of balanocarpol successfully improve the toxicity of balanocarpol on cancer cells along with improving its water solubility. The niosomes nanoparticles can be used in the future in the development of an effective balanocarpol based anticancer medications. 


\section{Conflicts of interest}

There are no conflicts to declare.

\section{Acknowledgements}

We gratefully acknowledge the Forest Research Institute Malaysia (FRIM) for the plant samples. 


\section{REFERENCES}

1. cancer IAFRo. Cancer Facts sheet 2018 [Available from: http://gco.iarc.fr/today/fact-sheetscancers.

2. Society AC. Special Section: Ovarian Cancer 2018 [Available from:

https://www.cancer.org/research/cancer-facts-statistics.html.

3. Obeid MA, Tate RJ, Mullen AB, Ferro VA. Lipid-based nanoparticles for cancer treatment. Lipid Nanocarriers for Drug Targeting: Elsevier; 2018. p. 313-59.

4. Wangchuk P. Therapeutic Applications of Natural Products in Herbal Medicines, Biodiscovery Programs, and Biomedicine2018. 1-20 p.

5. Basmadjian C, Zhao Q, Bentouhami E, Djehal A, Nebigil CG, Johnson RA, et al. Cancer wars: natural products strike back. Frontiers in Chemistry. 2014;2(20).

6. Khadra I, Obeid MA, Dunn C, Watts S, Halbert G, Ford S, et al. Characterisation and optimisation of diclofenac sodium orodispersible thin film formulation. International journal of pharmaceutics. 2019;561:43-6.

7. Li F-s, Weng J-K. Demystifying traditional herbal medicine with modern approach2017. nplants2017109 p.

8. Barbuti AM, Chen Z-S. Paclitaxel Through the Ages of Anticancer Therapy: Exploring Its Role in Chemoresistance and Radiation Therapy. Cancers. 2015;7(4):2360-71.

9. Obeid MA, Al Qaraghuli MM, Alsaadi M, Alzahrani AR, Niwasabutra K, Ferro VA. Delivering natural products and biotherapeutics to improve drug efficacy. Therapeutic delivery. 2017;8(11):947-56.

10. Tnah L, Lee S, Ng K, Lee CT, Bhassu S, Othman DR. Phylogeographical Pattern and Evolutionary History of an Important Peninsular Malaysian Timber Species, Neobalanocarpus heimii (Dipterocarpaceae)2012.

11. Diyasena MNC, Sotheeswaran S, Surendrakumar S, Balasubramanian S, Bokel M, Kraus W. Balanocarpol, a new polyphenol from Balanocarpus zeylanicus(trimen) and Hopea jucunda(Thw.)(Dipterocarpaceae). Journal of the Chemical Society, Perkin Transactions 1. 1985(0):1807-9.

12. Lim KG, Gray Al, Pyne S, Pyne NJ. Resveratrol dimers are novel sphingosine kinase 1 inhibitors and affect sphingosine kinase 1 expression and cancer cell growth and survival. British journal of pharmacology. 2012;166(5):1605-16.

13. Atun S, Aznam N, Arianingrum R, Niwa M. BALANOCARPOL AND HEIMIOL A, TWO RESVERATROLS DIMER FROM STEM BARK Hopea mengarawan (Dipterocarpaceae) 2006.

14. Manshoor N, Weber J-FF. Mass Spectrometric Analysis for Discrimination of Diastereoisomers. Mass Spectrometry Letters. 2015;6(4):99-104.

15. Chichioco Hernandez CL, Villaseñor IM, Schroeder FC, Paulus H, Clardy J. Stilbenoids from Hopea acuminata. Journal of Herbs, Spices \& Medicinal Plants. 2016;22(1):92-104.

16. Robinson K, Mock C, Liang D. Pre-formulation studies of resveratrol. Drug development and industrial pharmacy. 2015;41(9):1464-9.

17. Al Qaraghuli MM, Alzahrani AR, Niwasabutra K, Obeid MA, Ferro VA. Where traditional drug discovery meets modern technology in the quest for new drugs. Annals of pharmacology and pharmaceutics. 2017;2(11):1-5.

18. Nunes S, Madureira AR, Campos D, Sarmento B, Gomes AM, Pintado M, et al. Solid lipid nanoparticles as oral delivery systems of phenolic compounds: overcoming pharmacokinetic limitations for nutraceutical applications. Critical reviews in food science and nutrition. 2017;57(9):1863-73.

19. Ramalingam P, Ko YT. Improved oral delivery of resveratrol from N-trimethyl chitosan-gpalmitic acid surface-modified solid lipid nanoparticles. Colloids and Surfaces B: Biointerfaces. 2016;139:52-61.

20. Marianecci C, Di Marzio L, Rinaldi F, Celia C, Paolino D, Alhaique F, et al. Niosomes from 80s to present: the state of the art. Advances in colloid and interface science. 2014;205:187-206. 
21. Obeid MA, Khadra I, Mullen AB, Tate RJ, Ferro VA. The effects of hydration media on the characteristics of non-ionic surfactant vesicles (NISV) prepared by microfluidics. International journal of pharmaceutics. 2017;516(1-2):52-60.

22. Obeid MA, Gebril AM, Tate RJ, Mullen AB, Ferro VA. Comparison of the physical characteristics of monodisperse non-ionic surfactant vesicles (NISV) prepared using different manufacturing methods. International journal of pharmaceutics. 2017;521(1-2):54-60.

23. Wilczewska AZ, Niemirowicz K, Markiewicz KH, Car H. Nanoparticles as drug delivery systems. Pharmacological reports. 2012;64(5):1020-37.

24. Obeid MA, Elburi A, Young LC, Mullen AB, Tate RJ, Ferro VA. Formulation of Nonionic Surfactant Vesicles (NISV) Prepared by Microfluidics for Therapeutic Delivery of siRNA into Cancer Cells. Molecular pharmaceutics. 2017;14(7):2450-8.

25. Obeid MA, Dufès $C$, Somani S, Mullen AB, Tate RJ, Ferro VA. Proof of concept studies for siRNA delivery by nonionic surfactant vesicles: in vitro and in vivo evaluation of protein knockdown. Journal of liposome research. 2018:1-10.

26. Obeid MA, Khadra I, Albaloushi A, Mullin M, Alyamani H, Ferro VA. Microfluidic manufacturing of different niosomes nanoparticles for curcumin encapsulation: Physical characteristics, encapsulation efficacy, and drug release. Beilstein Journal of Nanotechnology. 2019;10(1):1826-32.

27. Kastner E, Verma V, Lowry D, Perrie Y. Microfluidic-controlled manufacture of liposomes for the solubilisation of a poorly water soluble drug. International journal of pharmaceutics. 2015;485(1):122-30.

28. Lo CT, Jahn A, Locascio LE, Vreeland WN. Controlled self-assembly of monodisperse niosomes by microfluidic hydrodynamic focusing. Langmuir. 2010;26(11):8559-66.

29. Sahidin S, Hakim E, Juliawaty L, Syah Y, Din L, Ghisalberti E, et al. Cytotoxic Properties of Oligostilbenoids from the Tree Barks of Hopea dryobalanoides2005. 723-7 p.

30. Tanaka T, Ito T, Ido Y, Son TK, Nakaya K, linuma M, et al. Stilbenoids in the stem bark of Hopea parviflora. Phytochemistry. 2000;53(8):1015-9.

31. Xue Y-Q, Di J-M, Luo Y, Cheng K-J, Wei X, Shi Z. Resveratrol Oligomers for the Prevention and Treatment of Cancers. Oxidative Medicine and Cellular Longevity. 2014;2014:9.

32. Wu X, Xu Y, Zhu B, Liu Q, Yao Q, Zhao G. Resveratrol induces apoptosis in SGC-7901 gastric cancer cells. Oncology letters. 2018;16(3):2949-56.

33. Sun W, Wang W, Kim J, Keng P, Yang S, Zhang H, et al. Anti-cancer effect of resveratrol is associated with induction of apoptosis via a mitochondrial pathway alignment. Adv Exp Med Biol. 2008;614:179-86.

34. Tino AB, Chitcholtan K, Sykes PH, Garrill A. Resveratrol and acetyl-resveratrol modulate activity of VEGF and IL-8 in ovarian cancer cell aggregates via attenuation of the NF-KB protein. Journal of ovarian research. 2016;9(1):84-.

35. Francioso A, Mastromarino P, Restignoli R, Boffi A, d'Erme M, Mosca L. Improved stability of trans-resveratrol in aqueous solutions by carboxymethylated $(1,3 / 1,6)$-beta-D-glucan. J Agric Food Chem. 2014;62(7):1520-5.

36. Trela BC, Waterhouse AL. Resveratrol: Isomeric Molar Absorptivities and Stability. Journal of Agricultural and Food Chemistry. 1996;44(5):1253-7.

37. Alyamani $\mathrm{H}$, Obeid MA, Tate RJ, Ferro VA. Exosomes: fighting cancer with cancer. Therapeutic Delivery. 2019;10(1):37-61.

38. Atun S, Aznam N, Arianingrum R. Oligoresveratrol Isolated from Stem Bark of Hopea Odorata as Antioxidant and Cytotoxicity againt Human Cancer Cell Line. International Conference on Chemistry and Chemical Engineering. 2012;38:6-10. 